\title{
Cross-Countries Empirical Analysis Of GCC Financial Systems Instability
}

\author{
Hassan Mounir El-Sady, Cairo University, Egypt
}

\begin{abstract}
In literature, the drivers of each of the Gulf Co-operation Council (GCC) country financial system instability did not receive adequate attention to be investigated separately, since the GCC countries are perceived as one Oil \& Gas economy with the same financial risk drivers. This paper fills this gap by examining the relative importance of the financial risk drivers for each GCC country capitalizing on time series analysis and utilizing monthly rating of each GCC country's financial risk driver for the period of Jan. 2000 to Dec. 2013.

This paper argues that the drivers of each GCC's country financial system instability are different and have unalike explanatory power from one GCC country to another. Meanly, it examines the impact of Foreign Debt Service as a percentage of Exports of Goods and Services (FDS/EGS), Foreign Debt as a percentage of GDP (FD/GDP), Net International Liquidity as months of Import Cover (NIL/IC), Current Account as a percentage of Exports of Goods and Services (CA/EGS), and Exchange Rate Stability (EXRS) on each GCC country financial system instability.

In terms of financial risk rating, results show that NIL/IC has negative impacts on all GCC countries financial risk rating. For financial system instability, results indicate that it is driven by CA/EGS in Qatar, KSA, Oman and UAE, by FD/GDP in Kuwait and Bahrain. In terms of the explanatory power of the GCC financial risk, results revealed that FD/GDP has the highest explanatory power in the case f Kuwait, KSA and UAE, CA/EGS in the case of Qatar and Oman, while the FDS/EGS has the highest explanatory power in the case of Bahrain.
\end{abstract}

Keywords: Country Financial Risk Rating; GCC's Financial Systems Instability; Exchange Rate; Net International Liquidity; Foreign Debt

\section{INTRODUCTION}

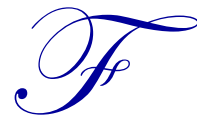
or investment decision making, understanding the macro-drivers of the country political, economic and financial risk became very crucial. It was shown in literature that political, economic and financial systems stability plays an essential rule to stimulate foreign direct and indirect investment in developed markets. Recently, examining the drivers of emerging country political, economic and financial systems instability received increasing attention in the literature. Yet, the drivers of GCC countries financial system instability have not been examined individually or collectively. In literature, GCC countries are characterized by the analysts as one Oil \& Gas economy with the same political, economic and financial risk drivers. Repeatedly, researchers analyzed the GCC capital markets via Kingdom of Saudi Arabia (KSA) ignoring different drivers of financial, economic and political risk for each GCC country. The insufficient analysis of each GCC country's financial risk deterred the allocation of international capital to the GCC countries. Moreover, the unclear determinants of GCC financial and economic risk drivers accelerated the allocation of GCC's direct and indirect investment outside the region.

This paper provides the first empirical analysis for the drivers of each GCC's country financial risk rating that instable the GCC financial systems. These ought to assist local and international investors in their investment decisions by providing a list of the most vital and volatile driver(s) of GCC's country financial risk. Also, this study highlights the weaknesses of the GCC financial systems which influence the allocation of international and/or local capital in the GCC region and negatively affect countries' investment profiles. 


\section{LITERATURE REVIEW}

In terms of the GCC, the study of each country financial risk drivers that cause the instability of their country financial system did not receive the adequate attention in literature. Investigating the drivers of GCC capital markets instability, Onour (2007) showed that speculative factors that determine oil prices play significant roles in driving GCC capital markets return. El-Sady and Sultanova (2012) signified that macro-drivers of GCC economic risk play crucial role in driving GCC economic system instability.

In terms of emerging markets, Vij and Kapoor (2007) examined the drivers of India's risk rating. Results reveal Indian risk rating is driven by economic risk than financial or political risk. Examining the causality between country financial risk and investment portfolios, El-Sady et al. (2003 A, B, C) indicates that drivers of country financial risk have more impact on equity return in emerging markets than in developed markets. Results from Clark and Tunaru (2001) show that investment decisions in emerging market are driven by the political risk factors; while the findings of Flannery and Protopapadakis (2001) point out that the allocation of capital in the international capital markets is driven by the economic risk factors. Questioning the drivers of capital market return, Diamonte et al. (1996) explain that determinants of country political risk plays more significant roles in driving emerging market returns than developed markets returns. Investigating the drivers of capital markets and financial systems development; El-Sady et al. (2009) show that country financial, economic and political risk play an essential role in driving financial systems creditworthiness in forty one developed and emerging economies.

Bilson et al. (1999) illustrates that the drivers of emerging stock markets return's volatility are more related to the country risk rather than to the world risk. Therefore, they suggested to analyze emerging capital markets separately rather than as a part of the international market. Findings of Bilson et al. (1999) revealed that specific country risk played more important role in allocating capital in emerging than in developed capital markets.

Exploring what formulate specific country risk, Vij (2005) indicates that drivers of emerging markets financial, economic and political risk can serve as good proxies of these countries risk. Investigating the drivers of Latin America's emerging markets risk, El-Sady et al. (2003, B) provided strong evidences that market risk in Latin America is driven by the country financial and economic risk. These evidences were supported results related to emerging markets from the Middle East and Africa as explained by El-Sady et al. (2003, A). Chen et al. (2005) indicates that political risk plays a key role in driving emerging markets risk. Investigating the impact of country risk on the capital market risk and return within the context of developed markets, El-Sady et al. (2003, C) shows evidences that country risk played an important role in driving the developed markets risk and return.

Analyzing the relationship between macro drivers of country risk and investment decisions, Chen et al. (2005), Khoury (2003), and Clark and Radu (2001) recommended that the country risk drivers can advance investment decisions in respect to international capital allocation. Hoti (2004) and Diamonte et al. (1996) provide strong evidences which support the relationship between macro-drivers of country risk and related markets risk and return. These results supported by Chen et al. (2005) and Vij (2005). Reported results of Vij (2005), Hoti (2004), and Flannery and Protopapadakis (2001) specify that country economic risk has a predictive power of related capital market's risk and return.

Our review of literature demonstrates that GCC country financial risk and financial systems instability did not receive adequate attention. Therefore, the aim of this study is to fill this gap in literature by performing the first empirical analysis to examine the drivers of GCC's financial risk and financial systems instability. By means of emphasizing the most influencing source of GCC financial systems instability, our results can guide international investors in their capital allocation decision within the GCC region. Additionally, this study aims to put a roadmap for GCC's policy makers to advance their financial systems for better financial risk rating of GCC countries and financial systems stability.

\section{RESEARCH DATA AND METHODOLOGY}

Rating different countries ability to fulfill their financial obligations has been provided in quantitative and qualitative measures by different rating agencies. Questioning the accuracy of risk rating agencies, Hoti and McAleer (2004) advised that ratings provided by the International Country Risk Guide (ICRG) could be used for 
empirical studies. Country risk indicators are provided on a monthly quantitative basis by the ICRG. The other rating agencies of country risk provide a single index of risk rating utilizing a mix of quantitative and qualitative indicators, which cannot be used for empirical studies. In principle, Country Financial Risk (CFR) rate provided by the ICRG measures the ability of each country to finance its official, commercial, and trade debt obligations. The total numbers of points assigned to any CFR is 50 points and distributed over five drivers of financial risk. Each of FD/GDP, FDS/EGS and EXRS assigned a total of 10 points, while CA/EGS and NIL/IC are assigned 15 and 5 points respectively. All measures for a given period are converted into U.S. dollars at the average exchange rate for that period. In term of risk, the ICRG classify any driver of financial risk with $0.00 \%-49.5 \%, 50 \%-59.5 \%, 60 \%$ $69.5 \%, 70 \%-79.5 \%$, and $80 \%-100 \%$ of that driver's total points are considered as a source with very high risk, high risk; moderate risk; low risk, and a very low risk respectively.

This paper argues the causality between GCC financial systems instability and (1) FD/GDP, (2) FDS/EGS, (3) CA/EGS, (4) NIL/IC, and (5) EXRS. The previous five determinants serve the purpose of this study as independent variables and extracted from the periodically published reports by the ICRG for KSA, Kuwait, United Arab Emirates (UAE), Qatar, Sultanate of Oman (Oman), and Kingdome of Bahrain (Bahrain). Empirically, it investigates the influence of the mentioned predetermined set of financial risk drivers to explore which driver(s) cause the financial systems instability across the GCC. Using monthly financial risk ratings provided by the ICRG for GCC countries over the period from January 2000 to Dec. 2013, Ordinary Least Squares (OLS) estimator is utilized to examine the assumed relationship between each GCC country financial risk and their drivers. Measures are ex-ante since it is reasonable to expect that they could have impact on the country financial risk and financial system instability. The paper capitalizes on the analysis of variance (ANOVA) to test the adequacy of the model and to indicate the main explanatory variables for each GCC country financial risk.

\section{THE MODEL}

Our model examines the impacts of FD/GDP, FDS/EGS, CA/EGS, NIL/IC, and EXRS on the GCC financial risk rating and financial system instability. In the model, each GCC country financial risk is a function of its drivers of financial risk as shown by equation (1):

$$
C F R=f(F D / G D P, F D S / E G S, C A / E G S, N I L / I C, E X R S)
$$

The coefficients of the model are estimated using the following Ordinary Least Squares (OLS) model shown by equation (2):

$$
C F R_{i, t}=\alpha_{0}+\alpha_{1} F D / G D P_{i, t}+\alpha_{2} F D S / E G S_{i, t}+\alpha_{3} C A / E G S_{i, t}+\alpha_{4} N I L / I C_{i, t}+\alpha_{5} E X R S_{i, t}+\varepsilon_{i, t}
$$

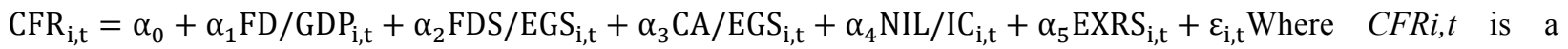
standardized vector of country $i$ financial risk at time $t, F D / G D P_{i, t}, F D S / E G S_{i, t}, C A / E G S_{i, t}, N I L / E G S_{i, t}$ and $E X R S_{i, t}$ are a standardized vector of country $i$ financial risk at time $t$, Foreign Debt as a percentage of GDP at time $t$, Foreign Debt Service as a percentage of Exports of Goods and Services at time $t$, Current Account as a percentage of Exports of Goods and Services at time $t$, Net International Liquidity as months of Import Cover at time $t$ and Exchange Rate Stability at time $t$, respectively. The coefficients of the model are represented by as while $\varepsilon_{i, t}$ is the random error term. The standardized vector value is $(x-x) / S D$, where $x$ is a vector of observed values, $x$ xis a vector of mean values, and $S D$ is a vector of Standards Deviation (Std. Dev.).

\section{ANALYSIS OF DESCRIPTIVE STATISTICS}

As shown by table (1) and according to the ICRG rating system, the GCC region enjoys very low financial risk with high average rating points of 43.95 , over the study period, counting for $87.90 \%$ with Std. Dev. of 0.881 . The high rating points of GCC financial risk is reflected in the low financial system risk which is driven by the perfect EXRS rating, followed by CA/EGS and FDS/EGS with an average of $91 \%$, and $90.5 \%$ of the allocated rating points for each, respectively. The GCC financial system is illiquid in essence of NIL/IC which counts for 2.90 points of the total rating points representing high risk with 58\%. In term of GCC financial systems instability, table (1) shows that it is driven by the high Std. Dev. of CA/EGS and NIL/IC counting for 1.096 and 0.917 followed by FD/GDP with Std. Dev. of 0.77 . Results reported by table (1) show that GCC enjoys perfect exchange rate stability. 
Table 1. Descriptive Statistics of GCC's Financial Risk (Jan. 2000 - Dec. 2013)

\begin{tabular}{lcccccc}
\hline & CFR & FD/GDP & FDS/EGS & CA/EGS & NIL/IC & EXRS \\
\hline Max. Rating Points & 48.55 & 10.00 & 10.00 & 15.00 & 5.00 & 10.00 \\
Min. Rating Points & 29.50 & 2.45 & 6.95 & 7.50 & 1.00 & 10.00 \\
Mean (Points) & 43.95 & 8.70 & 9.05 & 13.65 & 2.90 & 10.00 \\
Mean (\%) & $87.9 \%$ & $87.0 \%$ & $90.5 \%$ & $91.0 \%$ & $58.0 \%$ & $100 \%$ \\
Std. Deviation & 0.881 & 0.770 & 0.475 & 1.096 & 0.917 & 0.000 \\
\hline
\end{tabular}

Source: Author's calculations based on ICRG's published data.

It was shown by table (1) that GCC financial system is illiquid in term of NIL/IC. Tables (2) and (6) revile that the illiquidity of GCC financial systems is driven by the illiquidity of Bahrain and Oman financial systems with their low rating points of 2.35 and 2.45 respectively, which classify them as countries with very high liquidity risk. Also, tables (7) and (5) show that UAE and Qatar contribute to the illiquidity of the GCC financial system with their low rating points of 2.75 and 2.95 respectively, which classify them as countries with high liquidity risk.

The GCC's financial system instability in term of GCC's Std. Dev. of CA/EGS counting for 1.096 is driven by the instability of Qatar, KSA and Oman CA/EGS with their Std. Dev. of 2.108, 1.542 and 1.278 respectively as shown by tables (5), (3) and (6). Although Bahrain and Oman contribute more than any other GCC countries to the low rating of GCC's NIL/IC, they show stability with their low Std. Dev. of 0.528 and 0.562 , respectively as shown by tables (2) and (6). Table (4) shows that Kuwait enjoys the highest rate and the second lowest Std. Dev. of financial risk rating.

Although financial risk rating for Bahrain is not the highest in GCC, reported results in table (2) reveal that Bahrain has very high rating points, where its rating points, on average, over the study period reach 42 points as minimum, 44.25 points as maximum with 43.51 points on average. The high rating points of Bahrain position it within countries with very low financial risk. Also, Bahrain enjoys a very low Std. Dev. of 0.682, which position Bahrain as the county with the most stable financial system in GCC. The very low financial risk of Bahrain is due to the very high rank of its EXRS, FD/GDP, FDS/EGS, and CA/EGS with $100 \%, 95.5 \%, 90.5 \%$ and $83 \%$ of the total points assigned for each of these financial risk determinants, respectively. On the other hand, NIL/IC reflects a potential source of risk for Bahrain's financial system, counting for $47 \%$ of total points assigned to it. These figures give Bahraini market a financial edge which justifies the fact that the government of Bahrain had set their market to be the GCC's financial hub.

Table 2. Descriptive Statistics of Bahrain's Financial Risk (Jan. 2000-Dec. 2013)

\begin{tabular}{|c|c|c|c|c|c|c|}
\hline & CFR & FD/GDP & FDS/EGS & CA/EGS & NIL/IC & EXRS \\
\hline Max. Rating Points & 44.25 & 10.00 & 9.15 & 14.65 & 3.00 & 10.00 \\
\hline Min. Rating Points & 42.00 & 6.95 & 8.50 & 11.50 & 1.50 & 10.00 \\
\hline Mean (Points) & 43.65 & 9.55 & 9.05 & 12.45 & 2.35 & 10.00 \\
\hline Mean $(\%)$ & $87.3 \%$ & $95.5 \%$ & $90.5 \%$ & $83.0 \%$ & $47.0 \%$ & $100 \%$ \\
\hline Std. Deviation & 0.682 & 0.735 & 0.203 & 0.654 & 0.528 & 0.000 \\
\hline
\end{tabular}

Source: Author's calculations based on ICRG's published data.

Table (3) indicates that KSA, as classified by the ICRG, has a very low financial risk. It enjoys a very high financial risk rating of 46.15 points on average, which counts for $92.3 \%$ of the total points allocated for financial risk. The very high rating of KSA financial risk is driven by the very high rating of the Kingdom's EXRS, FDS/EGS, $\mathrm{CA} / \mathrm{EGS}$, and FD/GDP with $100 \%, 95 \%, 94.3 \%$, and $87 \%$, respectively, of total points assigned for each. The NIL/IC contributes negatively to the rating of KSA's financial risk with its low rating of $67 \%$ of total points allocated to it with $30 \%$ at minimum and $73 \%$ at maximum. The standard deviation of 0.894 points categorizes KSA as the second instable financial system in the GCC. The instability of KSA's financial system, in comparison to the other GCC countries, is driven by the high volatility of KSA's CA/EGS and NIL/IC with Std. Dev. of 1.542 and 1.169 points respectively. Also, table (3) shows that EXRS is the main contributor to the stability of KSA's financial risk with zero volatility. The zero volatility of EXRS is explained by the fact that KSA Riyal is pegged to the US dollar. 
Table 3. Descriptive Statistics of KSA's Financial Risk (Jan. 2000-Dec. 2013)

\begin{tabular}{lcccccc}
\hline & CFR & FD/GDP & FDS/EGS & CA/EGS & NIL/IC & EXRS \\
\hline Max. Rating Points & 48.15 & 10.00 & 10.00 & 15.00 & 3.65 & 10.00 \\
Min. Rating Points & 41.35 & 8.45 & 9.40 & 11.00 & 1.50 & 10.00 \\
Mean (Points) & 46.15 & 8.95 & 9.75 & 14.10 & 3.35 & 10.00 \\
Mean (\%) & $92.3 \%$ & $89.5 \%$ & $97.5 \%$ & $94.0 \%$ & $67.0 \%$ & $100 \%$ \\
Std. Deviation & 0.894 & 0.342 & 0.306 & 1.542 & 1.169 & 0.000 \\
\hline
\end{tabular}

Source: Author's calculations based on ICRG's published data.

Table (4), reveals that Kuwait has the highest financial risk rating point of 47.4 on average over the examination period, which counts for $94.8 \%$ of the total points and positioning Kuwait as a country with a very low financial risk; thus, Kuwait has the lowest financial risk among all GCC countries. Moreover, EXRS has been very stable over the study period with a very high rank of 100 percent. Although Kuwaiti Dinar is not pegged to the US dollar, the stability of the exchange rate is driven by managed float regime followed by the central bank of Kuwaiti. Also, table (4) shows that FDS/EGS and CA/EGS have a very high means of $95 \%$ and $94.3 \%$ respectively, setting Kuwait financial system on a very low financial risk category. The very high rating of FDS/EGS and CA/EGS indicate that Kuwait financial system has a major cash surplus. It is shown by table (4) that the stability of the Kuwaiti financial system is driven by EXRS, FDS/EGS, CA/EGS and NIL/IC with their low Std. Dev. of 0.00, 0.304, 0.347 and 0.486 respectively.

Table 4. Descriptive Statistics of Kuwait's Financial Risk (Jan. 2000-Dec. 2013)

\begin{tabular}{lcccccc}
\hline & CFR & FD/GDP & FDS/EGS & CA/EGS & NIL/IC & EXRS \\
\hline Max. Rating Points & 48.55 & 10.00 & 10.00 & 15.00 & 5.00 & 10.00 \\
Min. Rating Points & 43.85 & 6.50 & 9.10 & 13.25 & 2.50 & 10.00 \\
Mean (Points) & 47.40 & 8.70 & 9.50 & 14.15 & 3.65 & 10.00 \\
Mean (\%) & $94.8 \%$ & $87.0 \%$ & $95.0 \%$ & $94.3 \%$ & $73.0 \%$ & $100 \%$ \\
Std. Deviation & 0.763 & 1.047 & 0.304 & 0.347 & 0.486 & 0.000 \\
\hline
\end{tabular}

Source: Author's calculations based on ICRG's published data.

Table (5) discloses that Qatar ahs a moderate financial risk, but it is classified as the second risky financial system among GCC countries with its mean of 42.77 points. The moderate rating of Qatar's financial risk is explained by the very low rating of NIL/IC and FD/GDP with $59 \%$ and $74.2 \%$ of the total points allocated for each, respectively. Reported results by table (5) show that Qatar has the most instable financial system in the GCC region as indicated by its high Std. Dev. of 1.615 points. The high volatility of Qatar's financial risk is driven by the high Std. Dev. of CA/EGS of 2.108 points, followed by FDS/GDP, NIL/IC and FD/GDP with a Std. Dev. of 1.584, 1.294 and 1.097 points, respectively. The stability of Qatar's exchange rate is explained by the fact that Qatari Dinar is pegged to the US dollar.

Table 5. Descriptive Statistics of Qatar's Financial Risk (Jan. 2000-Dec. 2013)

\begin{tabular}{lcccccc}
\hline & CFR & FD/GDP & FDS/EGS & CA/EGS & NIL/IC & EXRS \\
\hline Max. Rating Points & 47.35 & 9.05 & 9.55 & 15.00 & 3.75 & 10.00 \\
Min. Rating Points & 29.50 & 2.45 & 7.50 & 8.50 & 1.00 & 10.00 \\
Mean (Points) & 42.77 & 7.42 & 8.65 & 13.75 & 2.95 & 10.00 \\
Mean (\%) & $85.5 \%$ & $74.2 \%$ & $86.5 \%$ & $91.7 \%$ & $59.0 \%$ & $100 \%$ \\
Std. Deviation & 1.615 & 1.097 & 1.584 & 2.108 & 1.294 & 0.000 \\
\hline
\end{tabular}

Source: Author's calculations based on ICRG's published data.

Given reported results in table (6), Oman's financial system is rated by the ICRG among the ones with the very low risk as measured by the mean of 42.35 points, which counts for $84.7 \%$ of the total points assigned to the country financial risk rating. The very low financial risk associated with the high rating points for Oman financial system is driven by the high rating points of $100 \%, 89.5 \%$, and $86.7 \%$ allocated for EXRS, FDS/EGS, and CA/EGS respectively. Although CA/EGS contributes positively to the high rating of Oman's financial risk rating, it contributes negatively to the stability of Oman's financial system with its high Std. Dev. of 1.279. Controversy, NIL/IC contributes negatively to Oman's financial risk rating with its low rating points of $49 \%$ and positively to the stability of the financial system with its low Std. Dev. of 0.562. Also, FDS/EGS and FD/GDP contribute to the stability of Oman financial system with their low Std. Dev. of 0.318 and 0.655 respectively. 
Table 6. Descriptive Statistics of Oman's Financial Risk (Jan. 2000-Dec. 2013)

\begin{tabular}{lcccccc}
\hline & CFR & FD/GDP & FDS/EGS & CA/EGS & NIL/IC & EXRS \\
Max. Rating Points & 45.00 & 9.10 & 9.50 & 14.50 & 3.35 & 10.00 \\
Min. Rating Points & 39.10 & 7.00 & 8.85 & 10.75 & 1.00 & 10.00 \\
Mean (Points) & 42.35 & 7.95 & 8.95 & 13.00 & 2.45 & 10.00 \\
Mean (\%) & $84.7 \%$ & $79.5 \%$ & $89.5 \%$ & $86.7 \%$ & $49.0 \%$ & $100 \%$ \\
Std. Deviation & 0.787 & .655 & 0318 & 1.278 & 0.562 & 0.000 \\
\hline
\end{tabular}

Source: Author's calculations based on ICRG's published data.

As shown by table (7), UAE experience very high rating points of 44, which place UAE as the third GCC country in term of financial risk. The very low UAE's financial risk is driven by EXRS, FDS/EGS and CA/EGS with 100\%, $96.5 \%$, and $91 \%$ of rating points for each, respectively. Moreover, UAE's financial system is the third instable system as indicated by its Std. Dev. of 0.824 points. The moderate Std. Dev. of the UAE is explained by the high volatility of CA/EGS and FD/GDP with 0.864 and 0.803 points, respectively. Also, reported results in table (7) reveal that EXRS and FDS/EGS contribute to the stability of UAE financial system. EXRS and FDS/EGS have the highest average rating points of $100 \%$ and $96.5 \%$ respectively, and the minimum volatility of 0.00 and 0.185 respectively, as measured by the Std. Dev. among other financial risk drivers. It worth to mention that EXRS stands idle at $100 \%$ of the given maximum rating of 10 points with zero volatility as a result of pegging the UAE Dirham to the US dollar.

Table 7. Descriptive Statistics of UAE's Financial Risk (Jan. 2000-Dec. 2013)

\begin{tabular}{lcccccc}
\hline & CFR & FD/GDP & FDS/EGS & CA/EGS & NIL/IC & EXRS \\
\hline Max. Rating Points & 45.15 & 9.15 & 10.00 & 15.00 & 3.55 & 10.00 \\
Min. Rating Points & 39.80 & 5.00 & 9.35 & 12.25 & 1.50 & 10.00 \\
Mean (Points) & 44.00 & 7.85 & 9.65 & 13.65 & 2.75 & 10.00 \\
Mean (\%) & $88.0 \%$ & $78.5 \%$ & $96.5 \%$ & $91.0 \%$ & $59.0 \%$ & $100 \%$ \\
Std. Deviation & 0.824 & 0.803 & 0.185 & 0.864 & 0.662 & 0.000 \\
\hline
\end{tabular}

Source: Author's calculations based on ICRG's published data.

In conclusion, results reported in tables (2) through (7) reveal that Kuwait has the lowest GCC's country financial risk with the average of $94.8 \%$ of the total points assigned for financial risk followed by KSA, UAE, Bahrain, Qatar and Oman with an average of $92.3 \%, 88 \%, 87.3 \%, 85.5 \%$ and $84.7 \%$ as shown by tables (3), (7), (2), (5) and (6), respectively. Again, the zero Std. Dev. of EXRS is explained by the fact that most of the GCC's currencies are pegged to US dollar or managed through a basket of currencies which dominated by US dollar. In terms of financial system stability, results reported by table (2) revealed that Bahrain has the most stable financial system in GCC given its low Std. Dev. of 0.682. Kuwait, Oman and UAE have below GCC's average Std. Dev. of 0.763, 0.787 and 0.824 points respectively, reflecting lower financial risk than GCC's on average. KSA has above GCC financial risk with Std. Dev. of 0.894 points. Our results pointed out that Qatar has the most instable financial system in the GCC region given that it has the highest Std. Dev. of 1.615 points of all GCC's country and its low rating points of 42.77 among all GCC countries.

\section{ANALYSIS OF EMPIRICAL RESULTS}

In modeling the relationship between country financial risk and its determinants, coefficients of equation (2) are estimated for each GCC country and results are reported by tables (8) through (13). Obtained results show a positive and significant relationship between GCC's country financial risk and their drivers of FD/GDP, FDS/EGS, CA/EGS, and NIL/IC. For the EXRS, the model did not show any significant relationship with any GCC country financial risk since it is constant over the study period. Therefore, the EXRS is omitted from the analysis. All results are significant at one percent significance level. This paper capitalized on the Analysis of Variance (ANOVA) to test the adequacy of our model. The obtained ANOVA estimates showed the adequacy of our model with $P$-Value close to zero. Therefore, one can conclude that the mean country risk is not the same for all determinants of the GCC's country financial risk.

Reported results in table (8) show that Bahrain's financial risk has a significant and positive relationship with the FD/GDP, FSD/EGS, CA/EGS, and NIL/IC. Results indicate that NIL/IC is the main driver of Bahrain's financial risk. Also, as shown in table (8), an increase of one rating point of NIL/IC will advance Bahrain's financial rating by 
$85.08 \%$ of that point. FDS/EGS and FD/GDP play a moderate role in driving Bahrain's financial risk, where one point increase in FDS/EGS and FD/GDP will advance the country's financial rating by $26.97 \%$ and $18.09 \%$ of that point respectively. CA/EGS has the least impact on Bahrain's financial risk since one rating point increase in CA/EGS advances the country's financial risk by only $7.87 \%$ of that point.

Also, table (8) indicates that the most influencing drivers of Bahrain's financial risk are FDS/EGS and FD/EGS. They explain $46.88 \%$ and $40.96 \%$ of the country's financial risk variability. CA/EGS explains $12.58 \%$ of the country's financial risk variation, while NIL/IC explains only $2.59 \%$ of Bahrain's financial risk variation.

Table 8. The OLS Estimates of Bahrain's Financial Risk Drivers

\begin{tabular}{lcccc}
\hline \multicolumn{1}{c}{ Variables } & Coefficients $(\boldsymbol{\alpha})$ & Seq. SS & $\boldsymbol{P}$-Value \\
\hline Constant & 0.0000005 & 0.00000 & 40.96 & 0.386 \\
FD/GDP & $0.1809^{* * *}$ & 0.00000 & 46.88 & 0.000 \\
FDS/EGS & $0.2697^{* * *}$ & 0.00000 & 12.58 & 0.000 \\
CA/EGS & $0.0787^{* * *}$ & 0.00000 & 2.59 & 0.000 \\
NIL/IC & $0.8508^{* * *}$ & 0.00000 & 0.000 \\
\hline
\end{tabular}

*** Refers to 1\% Significant Level. S.E. Stands for the Standard Error of the Estimate.

A significant and positive relationship between KSA's financial risk and its FD/GDP, FSD/EGS, CA/EGS, and NIL/IC are demonstrated by table (9). The main driver of KSA's financial risk is CA/EGS, where increasing the CA/EGS by one rating point will advance KSA's financial rating by $76.45 \%$ of that point. NIL/IC plays a moderate role in driving KSA's financial risk, where one point increase of it will advance the country's financial rating by $39.66 \%$ of that point. Finally, the increase of one point rating for FD/GDP and FDS/EGS can advance the KSA's financial risk by $19.47 \%$ and $14.30 \%$ of that point, respectively.

In terms of the explanatory power of the KSA's financial risk drivers, shown results by table (9) indicate that FD/GDP and FDS/EGS have the highest explanatory power for the country financial risk variability. FD/GDP and FDS/EGS can explain $33.07 \%$ and $32.34 \%$ of the KSA's financial risk. NIL explains $22.36 \%$, and CA explains $15.27 \%$ of the KSA financial risk.

Table 9. The OLS Estimates of KSA's Financial Risk Drivers

\begin{tabular}{lcccc}
\hline \multicolumn{1}{c}{ Variables } & Coefficients $(\boldsymbol{\alpha})$ & S.E & Seq. SS & \multicolumn{1}{c}{-Value } \\
\hline Constant & 0.0000000 & 0.00000 & 32.34 & 0.427 \\
FD/GDP & $0.1947^{* * *}$ & 0.00048 & 33.07 & 0.000 \\
FDS/EGS & $0.1430^{* * *}$ & 0.00066 & 15.27 & 0.000 \\
CA/EGS & $0.7645^{* * *}$ & 0.00066 & 22.36 & 0.000 \\
NIL/IC & $0.3966^{* * *}$ & 0.00045 & 0.000 \\
\hline
\end{tabular}

*** Refers to $1 \%$ Significant Level. S.E. Stands for the Standard Error of the Estimate.

For Kuwait, table (10) indicates that Kuwait financial risk is positively and significantly correlated with its determinants. It is shown that NIL/IC and CA/EGS are the key drivers of Kuwait's financial risk. Table (10) indicates that the increase by one point rating of NIL/IC and CA/EGS will escalate Kuwait's financial rating by $53.76 \%$ and $29.88 \%$ of that point, respectively. FDS/EGS plays a moderate role in driving the country financial risk where table (10) shows that an increase of FDS/EGS by one rating point will advance Kuwait's financial rating by $20.95 \%$ of that point. Also, table (10) reveals that FD/GDP plays a minimal role in driving Kuwait's financial risk. A one point increase of FD/GDP can advance the country financial rating by $6.43 \%$ of that unit, only.

Results reported in table (10) indicate that the most influencing source for Kuwait's financial risk is FD/GDP, which explains about $64.44 \%$ of Kuwait's financial risk variability, followed by NIL/IC and CA/EGS which explain $22.32 \%$ and $6.14 \%$ of Kuwait's financial risk variability. The FDS/EGS explains, only, $2.11 \%$ of Kuwait's financial risk variability. 
Table 10. The OLS Estimates of Kuwait's Financial Risk Drivers

\begin{tabular}{lcccc}
\hline \multicolumn{1}{c}{ Variables } & Coefficients $(\boldsymbol{\alpha})$ & S.E & Seq. SS & P-Value \\
\hline Constant & 0.0000000 & 0.00000 & 64.44 & 0.721 \\
FD/GDP & $0.0643^{* * *}$ & 0.00000 & 2.11 & 0.000 \\
FDS/EGS & $0.2095^{* * *}$ & 0.00000 & 6.14 & 0.000 \\
CA/EGS & $0.2988^{* * *}$ & 0.00000 & 22.32 & 0.000 \\
NIL/IC & $0.5376^{* * *}$ & 0.00000 & 0.000 \\
\hline
\end{tabular}

*** Refers to $1 \%$ Significant Level. $\quad$ S.E. Stands for the Standard Error of the Estimate.

The examination of the drivers of Qatar's financial risk indicates a significant and positive relationship between Qatar's financial risk and its determinants as reported in table (11). Results reveal that CA/EGS has the highest explanatory power; it explains $72.50 \%$ of Qatar's financial risk variability, while FD/GDP has a moderate explanatory power explaining $29.59 \%$ of the country's financial risk variability. Finally, it is shown by table (11) that NIL/EGS explains less than $1 \%$ of Qatar's financial risk variability, while FDS/EGS has a neglected explanatory power for Qatar' financial risk variability.

Results reported in table (11) explain that CA/EGS has a leading role in driving Qatar's financial risk. It is shown that one point increases in Qatar's CA/EGS rating will advance the country's financial risk rating by $66.45 \%$ of that rating point. Given that a one point increase in FD/EGS and NIL/IC ratings will advance Qatar's financial risk rating by $24.68 \%$ and $24.06 \%$ of that rating point, one can conclude that FD/EGS and NIL/IC have a moderate role in driving the country financial risk. By advancing Qatar's FDS/EGS by one rating point, the country financial risk will be advanced by $14.86 \%$ of that rating point.

Table 11. The OLS Estimates of Qatar's Financial Risk Drivers

\begin{tabular}{lcccc}
\hline \multicolumn{1}{c}{ Variables } & Coefficients $(\boldsymbol{\alpha})$ & S.E & & \multicolumn{1}{c}{ S-Value } \\
\hline Constant & -0.0000002 & 0.00010 & 29.59 & 0.402 \\
FD/GDP & $0.2468^{* * *}$ & 0.00000 & 0.01 & 0.000 \\
FDS/EGS & $0.1486^{* * *}$ & 0.00000 & 72.50 & 0.000 \\
CA/EGS & $0.6645^{* * *}$ & 0.00000 & 0.91 & 0.000 \\
NIL/IC & $0.2406^{* * *}$ & 0.00000 & 0.000 \\
\hline
\end{tabular}

*** Refers to $1 \%$ Significant Level. S.E. Stands for the Standard Error of the Estimate.

It is shown by table (12) that Oman's financial risk has a significant positive relationship with its FD/GDP, FSD/EGS, CA/EGS, and NIL/IC. Reported results suggest that one rating point increases in CA/EGS will advance Oman's financial rating by $64.92 \%$ of that rating point, while a one rating point increase in NIL/IC and FD/EGS will improve the country's financial rating by $40.42 \%$ and $37.06 \%$ of that rating point, respectively. As reported by table (12), a one rating point increases in Oman's FDS/EGS will advance the country's financial risk rating by $13.33 \%$ of that point. Therefore, one can concludes that Oman's financial risk rating is driven, mainly, by CA/EGS followed by CA/EGS, FD/GDP, and lastly by FSD/EGS.

Table 12. The OLS Estimates of Oman's Financial Risk Drivers

\begin{tabular}{lcccc}
\hline \multicolumn{1}{c}{ Variables } & Coefficients $(\boldsymbol{\alpha})$ & S.E & Seq. SS & \multicolumn{1}{c}{$\boldsymbol{P}$-Value } \\
\hline Constant & -0.0000019 & 0.00002 & 43.58 & 0.502 \\
FD/GDP & $0.3706^{* * *}$ & 0.00000 & 0.88 & 0.000 \\
FDS/EGS & $0.1333^{* * *}$ & 0.00000 & 48.86 & 0.000 \\
CA/EGS & $0.6492^{* * *}$ & 0.00000 & 9.68 & 0.000 \\
NIL/IC & $0.4042^{* * *}$ & 0.00000 & 0.000 \\
\hline
\end{tabular}

*** Refers to $1 \%$ Significant Level. S.E. Stands for the Standard Error of the Estimate.

In terms of the explanatory power of Oman financial risk's determinants, reported results in table (12) indicate that $\mathrm{CA} / \mathrm{EGS}$ and FD/GDP have the highest explanatory power for the country's financial risk. They can explain $48.86 \%$ and $43.58 \%$ of Oman's financial risk variability. NIL/IC can explain $9.68 \%$ of Oman's financial risk variability, while FDS/EGS explains less than $1 \%$ of the country financial risk variability.

Table (13) reports the results of UAE's financial risk. It reveals that UAE's financial risk has a significant and positive relationship with FD/GDP, which explains $58.42 \%$ of the country's financial risk. CA/EGS, FDS/EGS, and 
NIL/IC have a moderate explanatory power for UAE's financial risk and explain $18.75 \%, 14.89 \%$ and $10.95 \%$ of the country's financial risk variability.

Reported results in table (13) reveal that CA/EGS is the main driver of UAE's financial risk rating, where a one rating point increase in CA/EGS will improve the country's financial risk rating by $66.45 \%$ of that point; while a one rating point increase in FD/GDP and NIL/IC can advance UAE's financial risk rating by approximately $24.68 \%$ and $24.06 \%$ of that point, respectively. Finally, table (13) indicates that a one point rating increase in FDS/EGS can advance the UAE's financial risk rating by $14.86 \%$ of that point.

Table 13. The OLS Estimates of UAE's Financial Risk Drivers

\begin{tabular}{lcccc}
\hline \multicolumn{1}{c}{ Variables } & Coefficients $(\boldsymbol{\alpha})$ & Seq. SS & $\boldsymbol{P}$-Value \\
\hline Constant & -0.0000002 & 0.00010 & 58.42 & 0.642 \\
FD/GDP & $0.2468^{* * *}$ & 0.00000 & 14.89 & 0.000 \\
FDS/EGS & $0.1486^{* * *}$ & 0.00000 & 18.75 & 0.000 \\
CA/EGS & $0.6645^{* * *}$ & 0.00000 & 10.95 & 0.000 \\
NIL/IC & $0.2406^{* * *}$ & 0.00000 & 0.000 \\
\hline
\end{tabular}

*** Refers to $1 \%$ Significant Level. S.E. Stands for the Standard Error of the Estimate.

\section{DISCUSSION AND CONCLUSIONS}

Since Gulf Co-operation Council (GCC) countries did not receive adequate attention by researchers to investigate the drivers of their country financial risk and financial system instability, this paper aimed to fill this gap in literature by empirically examining the relative importance of GCC financial risk drivers in driving the related country financial risk rating and financial system instability utilizing time series analysis of monthly data for the period from January 2000 to Dec. 2013. This can assist local and international investors in their investment decisions making by providing them a list of the most important and volatile factors that drive GCC countries' financial risk.

All GCC countries of Bahrain, KSA, Kuwait, Qatar, Oman and UAE are included in the study. In particular, the impact of Foreign Debt as percentage of GDP (FD/GDP), Foreign Debt Service as a percentage of Exports of Goods and Services (FDS/EGS), Current Account as a percentage of Exports of Goods and Services (CA/EGS), Net International Liquidity as months of Import Cover (NIL/IC), and Exchange Rate Stability (EXRS) on the GCC financial risk rating and financial systems instability is examined. The previous five financial risk drivers served the purpose of the study as independent variables and were extracted from the periodically published reports by the ICRG.

The descriptive analysis of the results reported by tables (1) through (7) indicated that all GCC countries are considered, by the ICRG rating system, as countries of very low financial risk. In term of rating points, Kuwait is ranked first among the GCC countries with mean of 47.4 rating points followed by KSA, UAE, Bahrain, Qatar and Oman with means of $46.15,44,43.65,42.77$ and 42.35 rating points, respectively.

In terms of financial system stability, results revealed that Bahrain has the most stable financial system in GCC given its low Std. Dev. of 0.682. Kuwait, Oman and UAE have below GCC's average Std. Dev. of 0.763, 0.787 and 0.824 points respectively, reflecting lower financial risk than GCC's on average. KSA has above GCC financial risk with Std. Dev. of 0.894 points. Our results pointed out that Qatar has the most instable financial system in the GCC region given that it has the highest Std. Dev. of 1.615 points of all GCC's country and its low rating points of 42.77 among all GCC countries.

In terms of the main drivers of GCC financial risk; CA/EGS can be considered as the main driver of GCC counties' financial risk rating as it is reported in tables (8) through (13). It plays a major role in driving KSA, Qatar, Oman, and UAE financial risk rating. Also, CA/EGS played a moderate role in driving Kuwait's financial risk rating and lesser role in driving the financial risk rating of Bahrain. NIL/IC is considered as the second main driver of GCC financial risk rating. It played the main role in driving the financial risk rating of Bahrain. Also, it is shown by tables (8) through (13) that NIL/IC played moderate role in driving Kuwait, Oman, and UAE financial risk ratings. Lastly, results reported by tables (4) and (5) disclosed that NIL/IC plays lesser role in advancing Kuwait and Qatar financial risk ratings. 
Results reported in tables (8) to (13) show that FD/GDP played a major role in advancing the financial risk rating of UAE, moderate role in advancing the financial risk ratings of Oman and Qatar, while it played lesser roles in advancing KSA, Bahrain, and Kuwait financial risk rating. Tables (8) through (13) indicated that FDS/EGS was not the main driver of any GCC country financial risk rating over the study period. It played a moderate role in driving financial risk rating of KSA and Bahrain and lesser roles with Qatar, Kuwait, Oman, and UAE. Careful analysis of reported results in tables (8) through (13) revealed that financial risk systems were driven differently across the GCC. These findings support our initial argument that financial risk rating is determined differently across the GCC countries.

In terms of the explanatory power of the financial risk drivers, reported results in tables (8) through (13) revealed that FD/GDP has the highest explanatory power of financial risk variability in Kuwait, KSA, and UAE and the second highest explanatory in Oman, Bahrain, and Qatar. CA/EGS has the highest explanatory power of Qatar and Oman financial risk variability, the second explanatory power for UAE's financial risk variability, and the third explanatory power of financial risk variability in Bahrain, Kuwait, and KSA. Only in Bahrain, the FDS/EGS has the highest explanatory power of the country financial risk variability. It has the second explanatory power of financial risk variability in UAE, and the least explanatory power of financial risk variability in the rest of GCC countries. As shown by tables (8) through (13), NIL/IC had the second explanatory power of Kuwait's financial risk variability, the third for KSA, Oman, and Qatar, and the least explanatory power of financial risk variability in UAE and Bahrain. Also, these findings support our argument that financial risk determinants have different explanatory power for each of the GCC country financial risk variability.

\section{AUTHOR BIOGRAPHY}

Dr. Hassan Mounir El-Sady, is an Associate Professor of Finance at Business Department, College of Commerce, Cairo University. Dr. El-Sady was the Financial Consultant to Kuwait Council of Ministries, The Government Performance Follow-Up Agency and former Financial and Economic Advisor to the Chairman of Kuwait Stock Exchange and Board of Directors of Kuwait Saving \& Loans Bank (Currently, Credit Bank). Email: helsady2020@gmail.com

\section{REFERENCES}

Bilson, Brailsford, Hooper (1999). The explanatory power of political risk in emerging. Working Paper Series in finance 99-94 markets, Australia.

Chen, Dar-Hsin , Bin, Feng-Shun and Chen, Chun-Da (2005). The Impacts of Political Events on Foreign Institutional Investors and Stock Returns: Emerging Market Evidence from Taiwan. International Journal of Business, (10) 165-188.

Clark, Ephraim and Radu Tunaru (2001). Emerging market investing with Political risk. Multinational Financial Journal, 5 (3) 155-173.

Diamonte, Robin, Liew, John M. and Stevens, Ross L., (1996). Political risk in emerging and developed markets. Financial Analysts Journal, 52 (3) 9-12.

El-Sady, Hassan Mounir (2009). The Impact of Country Financial, Economic, and Political Risk on its Creditworthiness and Stock Market Development: Cross Sectional Analysis. Arab Journal of Administrative Sciences, 16 (3) 343-381.

El-Sady, Hassan M., M. Kabir Hassan, Neal c. Maroney, and Ahmed Telfah, A. (2003). Country Risk and Stock Market Volatility, Predictability, and Diversification in the Middle East and Africa. Economic System, (27) 63-82.

El-Sady, Hassan M., M. Kabir Hassan, and Oscar Varela, B. (2003). International Country Risk Guide's Country Risk Rating and Emerging Markets' Performance in Latin America. Journal of Emerging Markets, (8) 14-46.

El-Sady, Hassan Mounir, M. Kabir Hassan and William Sackley. C. (2003). The Role of Political, Financial and Economic Risk in Governing Volatility and Returns Predictability in Developed Equity Markets. International Journal of Applied Business \& Economic Research, 1 (2) 117-136.

El-Sady, Hassan M. and Vasilya Sultanova (2012). Cross Country Analysis of GCC Economic Risk. The Business \& Management Review, 2 (2) 267-277.

Hoti, Suhejla and McAleer, Michael (2004). An Empirical Assessment of Country Risk Ratings and Associated Models. Journal of Economic Surveys, 18 (4) 539-588.

Khoury, Sarkis Joseph (2003). Country Risk and International Portfolio Diversification for the Individual Investor. Financial Services Review, (12) 73-93.

Onour, Ibrahim A. Ahmed (2007). Impact of Oil Price Volatility on Gulf Cooperation Council Stock Markets' Return. OPEC Review, 31 (3) 171-189.

Flannery, Mark J. and Protopapadakis, Aris, (2001). Macroeconomic Factors Do Influence Aggregate Stock Returns. Review of 
Financial Study, 15 (3) 751-782.

Vij Madhu (2005). The Determinants of Country Risk Analysis An Empirical Approach. Journal of Management Research, 5 (1) 20-31.

Vij Madhu and Kapoor M. C. (2007). Country Risk Analysis A Case Study of India. Journal of Management Research, 7 (2) 87 102. 


\section{NOTES}

